\title{
Composite splenic marginal zone lymphoma and mantle cell lymphoma with p53 deletion and tetraploidization
}

\author{
David Azoulay ${ }^{*}$, Eugene Dementiev ${ }^{2}$, Luba Trakhtenbrot ${ }^{3}$, Netanel Horowitz ${ }^{4}$, Tamar Tadmor ${ }^{5}$ and Luiza Akria $^{1}$ \\ ${ }^{1}$ Hematology Unit and Laboratories, Galilee Medical Center, Naharia \& Azrieli Faculty of Medicine, Bar-Ilan University, Safed, Israel \\ ${ }^{2}$ Pathology Unit, Galilee Medical Center, Naharia, Israel \\ ${ }^{3}$ Department of Hematology, Sheba Medical Center, Tel-Hashomer, Israel \\ ${ }^{4}$ Department of Hematology \& BMT, Rambam Health Care Campus, Haifa, Israel \\ ${ }^{5}$ Department of Hematology, Bnai Zion Medical Center, Haifa, Israel
}

\begin{abstract}
Here we present unusual case of composite splenic marginal zone lymphoma (SMZL) and mantle cell lymphoma (MCL) that presented with P53 deletion and tetraploid DNA content.
\end{abstract}

\section{Case Report}

A 71-year-old woman referred to our medical center due to abdominal pain. She was found to have splenomegaly without lymphadenopathy. Her complete blood count was remarkable for mild anemia and thrombocytopenia $\left(41 \times 10^{3} / \mu \mathrm{L}\right)$. Her white blood cell count was $6.8 \times 10^{3} / \mu \mathrm{L}$, with a normal absolute lymphocyte count of 3.2 $\mathrm{x} 10^{3} / \mu \mathrm{L}$. Mature-appearing small lymphocytes and a few large atypical lymphocytes with blastic morphology and sharp vacuoles were seen in a peripheral blood smear (Figure 1A).

Flow cytometry of the peripheral blood demonstrated kapparestricted B lymphocytes that accounted for $50 \%$ of total lymphocytes. $80 \%$ of them were characterized by $\mathrm{CD} 19^{\text {high }}, \mathrm{CD} 20^{+}, \mathrm{CD} 5 \mathrm{CD} 22^{+}$, FSC $^{\text {low }} / \mathrm{SSC}^{\text {low }}$ profile and a diploid DNA content. The remaining $20 \%$ of $\mathrm{B}$ cells were characterized by $\mathrm{CD} 19^{\text {low }}, \mathrm{CD} 20^{+}, \mathrm{CD}^{+/ \text {- variable }} \mathrm{CD} 22^{++}$, FSC $^{\text {high }} / S_{S C}{ }^{\text {high }}$ profile and a tetraploid DNA content (Figure 1B). Both populations were negative for CD10, CD11c, CD23, CD43, CD103, CD200, LAIR-1, and expressed dim CD38 and low cytoplasmic IgD/ IgM. Flow cytometry of the bone marrow aspirate showed the same kappa-restricted B cells populations demonstrated in peripheral blood, and the large vacuolated lymphocytes were clearly visible in the film (Figure 1C I).

The bone marrow biopsy showed diffused cell infiltration with two different patterns, small/medium size cells and atypical vacuolated large cells. Both small and large cells stained positive for CD20 and PAX-5 that together accounted for $80 \%$ of the total hematopoietic cellularity. BCL-1 staining was positive mainly in the large cells. KI67 was positive in $20 \%$ of total cells. CD10, BCL-6, CD30, CD23, MUM1 and SOX-11 were negative (Figure 1C II-VI).

IgH-rearrangement by PCR showed monoclonality. PCR analysis for $\mathrm{t}(11 ; 14)$ was negative, however FISH analysis confirmed tetraploid karyotype including $\mathrm{t}(11 ; 14)(\mathrm{q} 13 ; \mathrm{q} 32)$ translocation in the large cells and not in the small cells. FISH analysis for BCL- 2 and BCL- 6 were negative in both populations. P53 was found to be deleted in all the large tetraploid cells as well as in a portion (16\%) of the small diploid cells (Table 1).

The patient received one cycle of attenuated $\mathrm{R}-\mathrm{CHOP}(60 \%)$ without significant clinical response. Therefore, therapy was substituted to the Bendamustine-Rituximab (BR) regimen. Flow cytometry that was done on peripheral blood one month after the first course revealed complete disappearance of the large tetraploid cells and residual diploid small CD5 negative kappa-restricted B cells that accounted for $10 \%$ of total lymphocytes. Two cycles of the BR protocol resulted in stable disease. Therefore, splenectomy was performed due to persistent splenomegaly (up to $26 \mathrm{~cm}$ ) and symptomatic refractory abdominal pain. Flow cytometry of the spleen showed no large tetraploid cells and residual diploid small CD5 negative kappa-restricted B cells that accounted for $4 \%$ of total lymphocytes. The reactive T-cells in the background were comprised of $65 \% \alpha \beta \mathrm{TcR}+\mathrm{T}$ cells and $35 \% \gamma \delta \mathrm{TcR}+\mathrm{T}$ cells. The spleen biopsy confirmed small aggregates of B lymphocytes in a background of reactive T-cells.

The patient in our case showed two restricted B cells subsets with distinct morphological, immuno-phenotypic and molecular characteristics at diagnosis. It wasn't clear whether these subsets

Table 1. $\%$ of positive nuclei

\begin{tabular}{|l|c|c|c|c|}
\hline & \multicolumn{4}{|c|}{ \% of positive nuclei } \\
\cline { 2 - 5 } & $\mathbf{t}(11 ; 14)$ & P53 deletion & BCL6 & $\mathbf{t}(\mathbf{1 4 ; 1 8})$ \\
\hline $\begin{array}{l}\text { Big near tetraploid nuclei } \\
\text { ( 15-20\% of total quantity } \\
\text { of nuclei) }\end{array}$ & 100 & 100 & 0 & 0 \\
\hline Normal size nuclei & 0 & 16 & 0 & 0 \\
\hline
\end{tabular}

*Correspondence to: David Azoulay, Ph.D, Hematology Unit, Galilee Medical Center, P.O.B 21 Naharia, 22100 Israel, Tel: 972-4-910-7657; Fax: 972-4-9107469; E-mail: davidA@GMC.gov.il

Received: September 13, 2018; Accepted: October 29, 2018; Published: November 02, 2018 

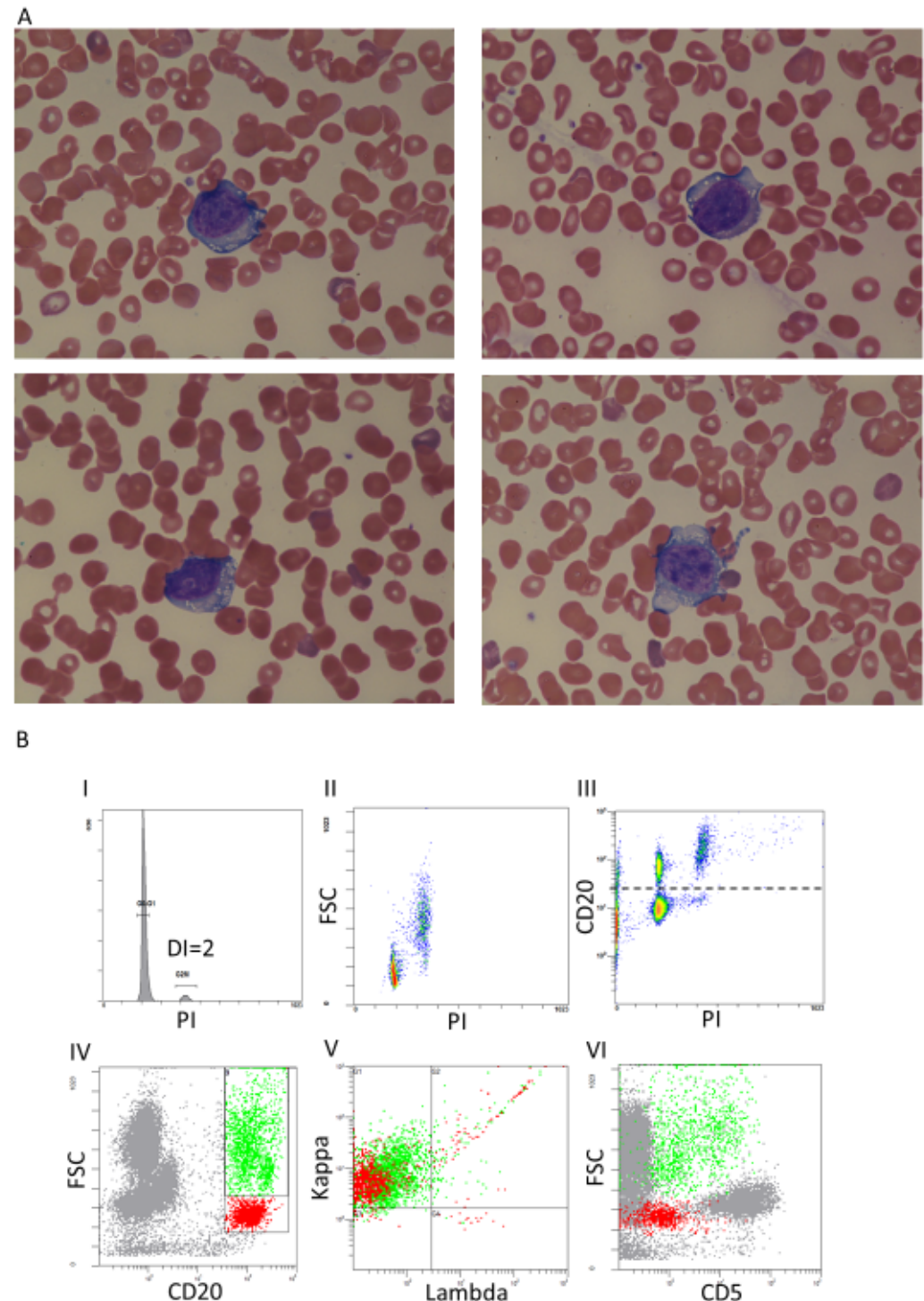

I

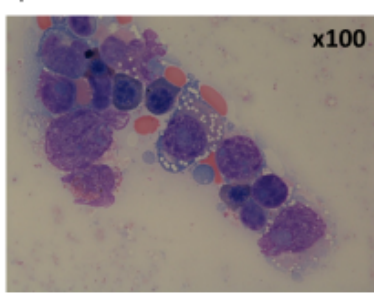

IV

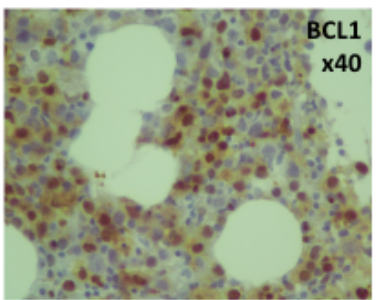

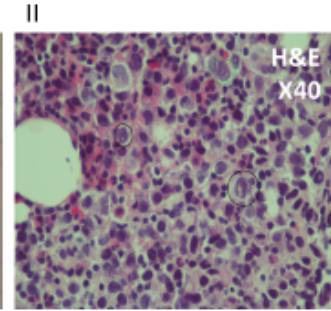

$\mathrm{V}$

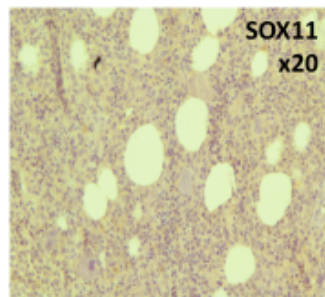

III

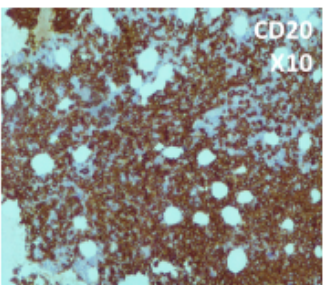

$\mathrm{VI}$

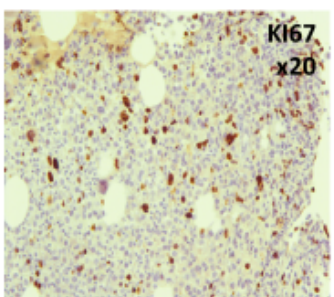

Figure 1. A. Peripheral blood-smear showing large atypical lymphocytes with sharp vacuoles. B. Flow cytometry of the peripheral blood showing cells with diploid and tetraploid DNA content (I), FSC ${ }^{\text {low }}$ profile in diploid and $\mathrm{FSC}^{\text {high }}$ profile in tetraploid cells (II), and CD20 expression in both diploid and tetraploid cells (III). Plot IV showing the FSC high/CD20 ${ }^{+}$large B cells in green and $\mathrm{FSC}^{\text {low }} / \mathrm{CD} 20^{+}$small B cells in red; both B-cell populations are Kappa restricted (V). $\mathrm{CD} 5$ is variably expressed on the $\mathrm{FSC}$ high $/ \mathrm{CD} 20^{+}$large B cells and not on the $\mathrm{FSC}$ low $/ \mathrm{CD} 20^{+}$ small B cells (VI). C. Atypical large vacuolated lymphocytes in the bone marrow aspiration (I). Small/medium size cells and atypical vacuolated large cells (marked with a circle) in bone marrow biopsy (II). Immuno-histochemistry for CD20 (III), BCL-1 (IV), SOX-11 (V), and KI67 (VI) 
represent coexistence of two distinct lympho-proliferative disorders or two variants of the same lympho-proliferative disorder. However, the findings of positive CD5 expression by flow cytometry and $t(11 ; 14)$ (q13; q32) translocation by FISH in the large cells and not in the small cells suggested that the large cells represented MCL.

The morphological, immune-phenotype and molecular characteristics of the small cells were different from classical MCL, Chronic Lymphocytic Leukemia, Follicular Lymphoma or Hairy Cell Leukemia. The complete absence of the $t(11 ; 14)(\mathrm{q} 13 ; \mathrm{q} 32)$ translocation in the small cells makes the possibility of a CD5 negative MCL variant [1] unlikely. The lower CD38 and cytoplasmic IgM expression and lack of other typical features such as plasmacytic differentiation, Dutcher bodies or increase mast cells in the bone marrow made their classification as Lympho-plasmacytic Lymphoma unlikely. Considering the massive splenomegaly $(25 \mathrm{~cm}$ by US at diagnosis), lack of lymphadenopathy and the relatively low lymphocytosis in the patient, the small B cells could possibly represent SMZL admixed with the MCL as was previously shown in other reported cases [2-4].

A remarked tendency to harbor chromosome numbers in the tetraploid range was previously reported in pleomorphic blastoid variants of MCL which are known to have an aggressive behavior [5]. However, lack of SOX11 and the weak CD5 expression as we found in our case were shown to be associated with indolent MCL variant. Indeed it was shown that leukemic non-nodal MCL variant cells are frequently presented in indolent MCL [5]. As we reported on a previous Hairy cell leukemia variant case [6], the current case also demonstrated p53 deletion in two out of four chromosomes 17 in the tetraploid cells. As p53 was deleted in two chromosomes and not in three chromosomes, we assume that this deletion initially occurred in a diploid cell that later become tetraploid. Artificial introduction of p53 was shown to induce cell cycle arrest in cancer cells [6]. Although such evolution needs to be approved, these two unusual cases suggest that endogenous reacquisition of two functional P53 copies upon tetraploidization may cause cell cycle arrest, hence, diminishing disease proliferation and dissemination. This proposed mechanism may explain the unexpected lower proportion of the MCL cells as compared to the small cells.

\section{Conflict of interest}

All authors declare no conflict of interest.

\section{References}

1. Alvarez-Argote J, Bauer FA, Dasanu CA (2014) CD5 negative mantle cell lymphoma: a different clinical entity? Conn Med 78: 211-214. [Crossref]

2. Randen U, Yri OE, Tierens A, Heim S, Beiske K, et al. (2011) Mantle cell lymphoma with features of marginal-zone lymphoma. J Hematop 4: 7-11. [Crossref]

3. Golardi N, Velasco MR, Elghetany MT (2009) Marginal zone variant of mantle cell lymphoma: CD5-negative cyclin D1-positive variant posing a diagnostic dilemma. Pathology international 59: 317-321.

4. Mollejo M, Lloret E, Solares J, Bergua JM, Mateo M, et al. (1999) Splenic involvement by blastic mantle cell lymphoma (large cell/anaplastic variant) mimicking splenic marginal zone lymphoma. Am J Hematol 62: 242-246. [Crossref]

5. Ott G, Kalla J, Ott MM, Schryen B, Katzenberger T, et al. (1997) Blastoid variants of mantle cell lymphoma: frequent bcl-1 rearrangements at the major translocation cluster region and tetraploid chromosome clones. Blood 89: 1421-1429.

6. Azoulay D, Sonkin V, Akria L, Rozano Gorelick A, Trakhtenbrot L, et al. (2018) Hairy cell leukemia-variant without typical morphology and with near-tetraploid DNA content, Cytometry Part B. Clinical cytometry 94: 169-171.

Copyright: (C2018 Azoulay D. This is an open-access article distributed under the terms of the Creative Commons Attribution License, which permits unrestricted use, distribution, and reproduction in any medium, provided the original author and source are credited. 